\title{
Prevalence of Malaria and Sexually Transmitted and Reproductive Tract Infections in Pregnancy in Sub-Saharan Africa A Systematic Review
}

\begin{tabular}{l} 
R. Matthew Chico, MPH \\
\hline Philippe Mayaud, MD \\
\hline Cono Ariti, MSc \\
\hline David Mabey, MD \\
\hline Carine Ronsmans, MD \\
\hline Daniel Chandramohan, PhD \\
\hline HERE ARE 880000 STILLBIRTHS \\
and 1.2 million neonatal deaths ${ }^{2}$ \\
each year in sub-Saharan Africa. \\
Low birth weight $(<2.5 \mathrm{~kg})$, at-
\end{tabular} tributable to intrauterine growth retardation, preterm delivery, or both, is the leading risk factor for neonatal mortality. ${ }^{3}$ Intrauterine infection is implicated in stillbirth ${ }^{4}$ and is associated with $25 \%$ to $40 \%$ of preterm births. ${ }^{5}$ Sexually transmitted infections and reproductive tract infections (STIs/RTIs) ${ }^{6}$ and malaria ${ }^{7}$ are associated with adverse birth outcomes, but both may be mitigated with preventive or presumptive treatment or by repeated screening and treatment throughout the antenatal period. The extent to which either approach may be beneficial depends on the underlying prevalence of STIs/RTIs and malaria in pregnancy. This systematic review and meta-analysis provide estimates for the dual prevalence of STIs/RTIs and malaria in pregnancy among women attending antenatal care facilities in sub-Saharan Africa.

\section{METHODS}

We searched 3 databases, PubMed, MEDLINE, and EMBASE, in Novem-

\section{CME available online at www.jamaarchivescme.com} and questions on p 2109.

Context Malaria and sexually transmitted infections/reproductive tract infections (STIs/ RTIs) in pregnancy are direct and indirect causes of stillbirth, prematurity, low birth weight, and maternal and neonatal morbidity and mortality.

Objective To conduct a systematic review and meta-analysis of malaria and STI/ RTI prevalence estimates among pregnant women attending antenatal care facilities in sub-Saharan Africa.

Data Sources PubMed, MEDLINE, EMBASE, the World Health Organization International Clinical Trials Registry, and reference lists were searched for studies reporting malaria, syphilis, Neisseria gonorrhoeae, Chlamydia trachomatis, Trichomonas vaginalis, or bacterial vaginosis among pregnant women attending antenatal care facilities in sub-Saharan Africa.

Study Selection Included studies were conducted in 1990-2011 with open enrollment. Studies from South Africa, where malaria is no longer endemic, were excluded.

Data Extraction Point prevalence estimates were corrected for diagnostic precision. A random-effects model meta-analysis was applied to produce pooled prevalence estimates.

Results A total of 171 studies met inclusion criteria, providing 307 point prevalence estimates for malaria or STIs/RTIs and including a total of 340904 women. The pooled prevalence estimates (with 95\% Cls and number of women with positive diagnosis) among studies in 1990-2011 in East and Southern Africa were as follows: syphilis, 4.5\% (3.9\% -5.1\%; $\mathrm{n}=8346$ positive diagnoses), $N$ gonorrhoeae, $3.7 \%(2.8 \%-4.6 \% ; \mathrm{n}=626), C$ trachomatis, 6.9\% (5.1\%-8.6\%; $n=350)$, T vaginalis, $29.1 \%(20.9 \%-37.2 \% ; n=5502)$, bacterial vaginosis, 50.8\% (43.3\%-58.4\%; $n=4280)$, peripheral malaria, 32.0\% (25.9\%-38.0\%; $n=11688)$, and placental malaria, $25.8 \%(19.7 \%-31.9 \% ; n=1388)$. West and Central Africa prevalence estimates were as follows: syphilis, 3.5\% $(1.8 \%-5.2 \% ; n=851)$, N gonorrhoeae, 2.7\% (1.7\%-3.7\%; $n=73)$, C trachomatis, $6.1 \%(4.0 \%-8.3 \% ; n=357)$, T vaginalis, $17.8 \%(12.4 \%-23.1 \% ; n=822)$, bacterial vaginosis, 37.6\% (18.0\%-57.2\%; $n=1208)$, peripheral malaria, $38.2 \%(32.3 \%-44.1 \% ; n=12242)$, and placental malaria, 39.9\% $(34.2 \%-$ $45.7 \% ; n=4658)$.

Conclusion The dual prevalence of malaria and STIs/RTIs in pregnancy among women who attend antenatal care facilities in sub-Saharan Africa is considerable, with the combined prevalence of curable STIs/RTIs being equal to, if not greater than, malaria.

JAMA. 2012;307(19):2079-2086

www.jama.com

ber 2011 using Medical Subject Headings and free text terms, respectively; the World Health Organization (WHO)

Author Affiliations: Departments of Disease Control (Mr Chico and Dr Chandramohan), Clinical Research (Drs Mayaud and Mabey), Medical Statistics (Mr Ariti), and Infectious Disease Epidemiology (Dr Ronsmans) and the Malaria Centre (Mr Chico and Drs Mabey and Chandramohan),
International Clinical Trials Registry; and relevant reference lists to identify studies conducted between 1990-

London School of Hygiene and Tropical Medicine, London, England.

Corresponding Author: R. Matthew Chico, MPH, London School of Hygiene and Tropical Medicine, Keppel Street, Room 445, London WC1E 7HT, England (matthew.chico@lshtm.ac.uk). 
Figure 1. Identification, Screening, and Eligibility of Studies in the Meta-analysis

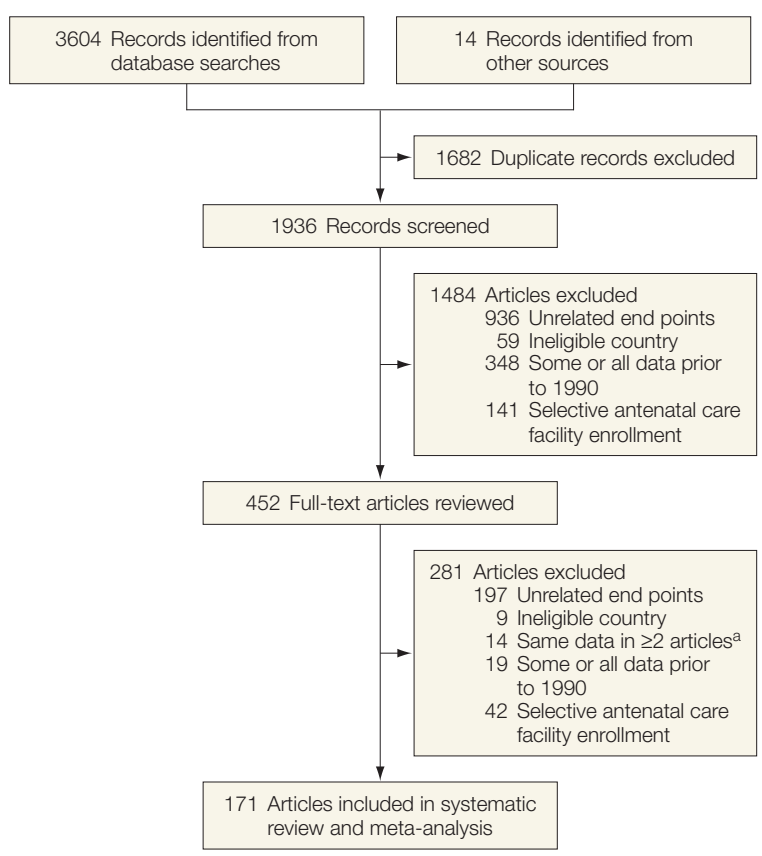

${ }^{a}$ Data believed to have appeared in more than 1 article were reviewed in full text and therefore do not appear under records excluded.

2011 that reported point prevalence estimates for STIs/RTIs, malaria, or both among pregnant women attending antenatal care facilities in sub-Saharan Africa (eAppendix 1; available at http: //www.jama.com). If 2 or more prevalence estimates were reportedwhether the result of a comparative diagnostic study, use of the same diagnostic method on multiple occasions, or subsequent use of a more sensitive assay-we used the higher/highest measurement in our analysis.

Our aim was to establish the dual prevalence of these infections in pregnancy among women receiving antenatal care without inflating estimates by including studies that selectively enrolled women from high-risk groups. Thus, studies that enrolled subsets of women from the antenatal care population were excluded (eg, only pregnant women with human immunodeficiency virus [HIV]). Studies of commercial sex workers, women seeking treatment at STI facilities or family planning facilities, or nonpregnant women tested in community-based sur-

2080 JAMA, May 16, 2012-Vol 307, No. 19 veys were also excluded. Multiyear studies that included pre-1990 data were excluded, as were studies from South Africa, where malaria is no longer endemic.

Records retrieved were all in English, although several abstracts had been translated from Chinese, Danish, Dutch, French, German, Italian, Portuguese, and Swedish. One author (R.M.C.) conducted the data retrieval. Data abstraction was not blinded to author or publication but was performed independently and in duplicate by R.M.C. and a research assistant, reviewing records against inclusion/exclusion criteest. Any discrepancies were resolved by another researcher assisted R.M.C. in the identification and classification of STI/RTI diagnostic methods; D.C. did the same with R.M.C. for malaria studies. No evidence of publication bias was found using funnel-plot assessment as described by Sterne et al. ${ }^{8}$ Given that data for this review have been drawn from studies reporting point prevaria to identify 3618 records of interD.C. Two authors (P.M. and D.M.) and lence estimates without intervention, the potential for publication bias should be minimal.

Point prevalences and 95\% confidence intervals were calculated for each study. We then applied a standard method $^{9}$ for correcting errors of magnitude with the known sensitivity and specificity of individual assays (eAppendix 2 and eAppendix 3) to increase the precision of each point prevalence estimate. Corrected point prevalence data were then used to generate pooled prevalence estimates and corresponding 95\% confidence intervals. We stratified results by subregion (East and Southern Africa vs West and Central Africa) because of underlying differences in epidemiology, particularly the extent to which HIV modulates the transmission of malaria and STIs/RTIs.

We conducted the meta-analysis with random-effects models, ${ }^{10}$ accounting for the possibility of heterogeneity between studies, and assessed our results with the Q statistic. Separate sensitivity analyses were performed for studies conducted before and after the year 2000 to examine temporal changes in prevalence. Using Stata/IC version 12 software ${ }^{11}$ to generate the randomeffects meta-analysis model, we produced forest plots to display the point prevalence and $95 \%$ confidence intervals of individual studies as well as the pooled estimates and $95 \%$ confidence intervals for all strata.

\section{RESULTS}

A total of 171 studies met inclusion criteria, providing 307 point prevalence estimates and including a total of 340904 women. Search results are summarized in FIGURE 1. The TABLE summarizes the pooled mean prevalence estimates of 1990-2011 with subanalyses for 19901999 and 2000-2011. Results for the period 1990-2011 are presented in FIGURE 2, plotted by subregion along with the lowest and highest point estimates reported. Detailed analyses by infection type and subregion are available online (eTable 1 and eFigure 1 [syphilis], eTable 2 and eFigure 2 
Table. Pooled Mean Prevalence Estimates Among Pregnant Women Attending Antenatal Care Facilities in Sub-Saharan Africa No. of Women

\begin{tabular}{|c|c|c|c|c|c|c|c|c|c|}
\hline \multirow[b]{2}{*}{ Infection by Subregion } & \multirow[b]{2}{*}{$\begin{array}{l}\text { Pooled Mean } \\
\text { Prevalence, } \% \\
(95 \% \mathrm{Cl})^{\mathrm{a}}\end{array}$} & \multicolumn{3}{|c|}{ No. of Women } & \multirow[b]{2}{*}{$\begin{array}{c}\text { Study } \\
\text { Sample Size, } \\
\text { Range }\end{array}$} & \multirow[b]{2}{*}{$\begin{array}{c}\text { No. of } \\
\text { Countries }\end{array}$} & \multirow[b]{2}{*}{$\begin{array}{l}\text { No. of } \\
\text { Studies }\end{array}$} & \multirow[b]{2}{*}{$\begin{array}{c}\text { ANC } \\
\text { Facilities } \\
\text { per Study, } \\
\text { Range }\end{array}$} & \multirow[b]{2}{*}{$\underset{\%}{\text { Heterogeneity, }}$} \\
\hline & & Positive & Tested & $\begin{array}{c}\text { Median } \\
\text { No. With } \\
\text { Positive } \\
\text { Diagnosis }\end{array}$ & & & & & \\
\hline \multicolumn{10}{|c|}{$1990-2011$} \\
\hline $\begin{array}{l}\text { East and Southern Atrica } \\
\text { Syphilis }\end{array}$ & 4.5 (3.9 to 5.1) & 8346 & 136686 & 54 & $85-52405$ & 11 & 41 & $1-57$ & c \\
\hline N gonorrhoeae & 3.7 (2.8 to 4.6$)$ & 626 & 17220 & 20 & $145-9104$ & 7 & 14 & $1-13$ & 87.5 \\
\hline C trachomatis & $6.9(5.1$ to 8.6$)$ & 350 & 5159 & 34 & $151-964$ & 8 & 10 & $1-13$ & 85.9 \\
\hline$T$ vaginalis & 29.1 (20.9 to 37.2) & 5502 & 28189 & 86 & $100-9137$ & 9 & 18 & $1-13$ & c \\
\hline Bacterial vaginosis & 50.8 (43.3 to 58.4$)$ & 4280 & 14112 & 245 & $100-3046$ & 8 & 11 & $1-13$ & c \\
\hline Peripheral parasitemia & 32.0 (25.9 to 38.0$)$ & 11688 & 47443 & 195 & $86-5093$ & 8 & 35 & $1-10$ & c \\
\hline Placental parasitemia & 25.8 (19.7 to 31.9) & 1388 & 6649 & 86 & $85-2502$ & 7 & 12 & $1-9$ & c \\
\hline $\begin{array}{l}\text { West and Central Africa } \\
\text { Syphilis }\end{array}$ & 3.5 (1.8 to 5.2$)$ & 851 & 10797 & 18 & $205-4100$ & 9 & 11 & $1-98$ & c \\
\hline Ngonorrhoeae & 2.7 (1.7 to 3.7) & 73 & 2737 & 17 & $230-1160$ & 8 & 5 & $1-4$ & 67.2 \\
\hline C trachomatis & 6.1 (4.0 to 8.3) & 357 & 5414 & 35 & $261-1160$ & 8 & 10 & $1-4$ & 94.7 \\
\hline$T$ vaginalis & 17.8 (12.4 to 23.1$)$ & 822 & 9806 & 57 & $86-2657$ & 7 & 12 & $1-4$ & c \\
\hline Bacterial vaginosis & 37.6 (18.0 to 57.2$)$ & 1208 & 7435 & 138 & $350-2657$ & 6 & 7 & $1-3$ & c \\
\hline Peripheral parasitemia & 38.2 (32.3 to 44.1$)$ & 12242 & 43312 & 127 & $26-6370$ & 10 & 56 & $1-55$ & c \\
\hline Placental parasitemia & 39.9 (34.2 to 45.7$)$ & 4658 & 27535 & 168 & $36-8310$ & 8 & 23 & $1-6$ & c \\
\hline \multicolumn{10}{|c|}{ 1990-1999 } \\
\hline $\begin{array}{l}\text { East and Southern Africa } \\
\text { Syphilis }\end{array}$ & 6.1 (5.0 to 7.2$)$ & 6168 & 97055 & 79 & $85-52405$ & 8 & 21 & $1-23$ & c \\
\hline Ngonorrhoeae & 3.7 (2.7 to 4.6$)$ & 547 & 15446 & 18 & $151-9104$ & 6 & 9 & $1-12$ & 82.5 \\
\hline C trachomatis & $9.4(6.0$ to 12.7$)$ & 194 & 2395 & 36 & $151-964$ & 4 & 5 & $1-12$ & 88.2 \\
\hline$T$ vaginalis & 32.8 (18.6 to 47.1$)$ & 4314 & 17710 & 74 & $100-9137$ & 5 & 10 & $1-12$ & c \\
\hline Bacterial vaginosis & 51.5 (35.5 to 67.5$)$ & 1876 & 7039 & 109 & $100-3046$ & 5 & 6 & $1-1$ & c \\
\hline Peripheral parasitemia & 34.9 (25.1 to 44.7$)$ & 7563 & 29068 & 327 & $102-5093$ & 7 & 16 & $1-10$ & c \\
\hline Placental parasitemia & 25.2 (16.0 to 34.3) & 588 & 3271 & 124 & $232-2502$ & 3 & 3 & 1 & c \\
\hline $\begin{array}{l}\text { West and Central Africa } \\
\text { Syphilis }\end{array}$ & 3.8 (1.5 to 6.2$)$ & 773 & 7106 & 13 & $205-4100$ & 6 & 17 & $1-4$ & c \\
\hline Ngonorrhoeae & 3.0 (1.8 to 4.2$)$ & 70 & 2507 & 18 & $350-1160$ & 7 & 4 & $1-4$ & 67.2 \\
\hline C trachomatis & 7.5 (4.6 to 10.0$)$ & 339 & 4632 & 44 & $350-1160$ & 7 & 5 & $1-4$ & 94.7 \\
\hline$T$ vaginalis & 23.5 (15.6 to 31.5$)$ & 721 & 4585 & 73 & $86-1160$ & 6 & 8 & $1-4$ & c \\
\hline Bacterial vaginosis & 46.0 (24.2 to 67.8$)$ & 640 & 2645 & 132 & $350-646$ & 5 & 5 & $1-3$ & c \\
\hline Peripheral parasitemia & 43.4 (34.1 to 52.7$)$ & 5543 & 16671 & 178 & $26-2104$ & 7 & 19 & $1-17$ & c \\
\hline Placental parasitemia & 42.6 (34.9 to 50.3) & 2445 & 19582 & 233 & $64-8310$ & 6 & 9 & $1-2$ & c \\
\hline \multicolumn{10}{|c|}{$2000-2011$} \\
\hline $\begin{array}{l}\text { East and Southern Atrıca } \\
\text { Syphilis }\end{array}$ & 2.9 (2.1 to 3.6$)$ & 2178 & 39631 & 32 & $245-17277$ & 8 & 17 & $1-57$ & c \\
\hline Ngonorrhoeae & $4.9(1.8$ to 7.9$)$ & 79 & 1774 & 21 & $145-835$ & 6 & 4 & $1-13$ & 91.9 \\
\hline C trachomatis & $5.2(3.4$ to 7.1$)$ & 156 & 2764 & 25 & $151-835$ & 6 & 5 & $1-13$ & 79.6 \\
\hline$T$ vaginalis & 24.9 (18.3 to 31.5$)$ & 1188 & 10479 & 98 & $151-2917$ & 8 & 8 & $1-13$ & c \\
\hline Bacterial vaginosis & 50.3 (43.9 to 56.7 ) & 2404 & 7073 & 253 & $247-2555$ & 6 & 5 & $1-13$ & c \\
\hline Peripheral parasitemia & 29.5 (22.4 to 36.5$)$ & 4125 & 18375 & 157 & $86-2459$ & 8 & 19 & $1-9$ & c \\
\hline Placental parasitemia & 26.5 (16.7 to 36.4 ) & 800 & 3378 & 58 & $85-726$ & 3 & 9 & $1-9$ & c \\
\hline \multicolumn{10}{|l|}{ West and Central Africa } \\
\hline N gonorrhoeae & $1.6(0.0$ to 3.3$)$ & 3 & 230 & 3 & 230 & 3 & 1 & $1-1$ & $N A^{b}$ \\
\hline C trachomatis & $1.9(0.2$ to 3.5$)$ & 18 & 782 & 9 & $261-521$ & 2 & 2 & $1-2$ & 55.8 \\
\hline$T$ vaginalis & 4.5 (2.5 to 6.6$)$ & 101 & 5221 & 25 & $201-2657$ & 2 & 4 & $1-4$ & 92.7 \\
\hline Bacterial vaginosis & $16.7(-12.6$ to 46.1$)$ & 604 & 4790 & 302 & 2133-2657 & 2 & 2 & $1-2$ & c \\
\hline Peripheral parasitemia & 35.1 (28.2 to 41.9$)$ & 6699 & 26641 & 97 & $38-6370$ & 8 & 36 & $1-55$ & c \\
\hline Placental parasitemia & 38.0 (28.4 to 47.6$)$ & 2213 & 7953 & 84 & $36-1875$ & 6 & 15 & $1-6$ & C \\
\hline \multicolumn{10}{|c|}{$\begin{array}{l}\text { Abbreviation: ANC, antenatal care; C trachomatis, Chlamydia trachomatis; } N \text { gonorrhoeae, Neisseria gonorrhoeae; T vaginalis, Trichomonas vaginalis. } \\
\text { a Note that dividing total No. of positive diagnoses by total No. of tested women does not account for diagnostic errors. A standard method }{ }^{9} \text { of correcting errors of known magnitude } \\
\text { has been applied to these data based on the sensitivity and specificity of individual diagnostic tests. Uncorrected and corrected point estimates from each study are presented } \\
\text { in the eTables. } \\
\text { b Not applicable (NA) because there is only } 1 \text { study. } \\
{ }^{\circ} \text { Heterogeneity greater than } 97.0 \% \text {. }\end{array}$} \\
\hline
\end{tabular}


[Neisseria gonorrhoeae], eTable 3 and eFigure 3 [Chlamydia trachomatis], eTable 4 and eFigure 4 [Trichomonas vaginalis], eTable 5 and eFigure 5 [bacterial vaginosis], eTable 6 and eFigure 6 [peripheral malaria], and eTable 7 and eFigure 7 [placental malaria]), with key findings reported herein. In all instances, prevalence estimates have been corrected to account for diagnostic errors as previously described.

\section{Syphilis}

The pooled mean prevalence of syphilis in East and Southern Africa was 4.5\% (95\% CI, 3.9\%-5.1\%), with the highest estimate, $13.7 \%$ (95\% CI, 9.0\%$18.5 \%$ ), in Vilanculos, Mozambique, based on rapid plasma reagin (RPR) testing and Treponema pallidum hemagglutination confirmation. ${ }^{12}$ In West and Central Africa, the pooled mean prevalence of serological syphilis was 3.5\% (95\% CI, 1.8\%-5.2\%). Yaoundé, Cameroon, reported the highest point esti- mate of $16.3 \%$ (95\% CI, 15.2\%-17.4\%) using a T pallidum hemagglutination assay that confirms syphilis infection, although not necessarily active cases. ${ }^{13}$

\section{Neisseria gonorrhoeae}

In East and Southern Africa, the pooled prevalence was $3.7 \%$ (95\% CI, 2.8\%$4.6 \%$ ), with the highest point estimate of $23.3 \%$ (95\% CI, 16.4\%-30.2\%) observed in Manhiça, Mozambique. ${ }^{12}$ The pooled mean prevalence of $N$ gonorrhoeae in West and Central Africa was $2.7 \%$ (95\% CI, 1.7\%-3.7\%); the highest individual estimate, $4.6 \%$ (95\% CI, 2.8\%$6.3 \%$ ), came from a study in Abidjan, Côte d'Ivoire, that used culture diagnostic methods. ${ }^{14}$

\section{Chlamydia trachomatis}

The pooled prevalence of $C$ trachomatis infection in East and Southern Africa was $6.9 \%$ (95\% CI, 5.1\%-8.6\%), with Khartoum, Sudan, reporting the highest prevalence estimate of $23.2 \%$ (95\%
CI, 16.5\%-29.9\%) as detected by an enzyme immunoassay. ${ }^{15}$ In West and Central Africa, the pooled mean prevalence was $6.1 \%$ (95\% CI, 4.0\%-8.3\%). The highest prevalence, $16.4 \%$ (95\% CI, $12.6 \%-20.1 \%$ ) based on culture or enzyme immunoassay, was observed in Pikine, Senegal. ${ }^{16}$

\section{Trichomonas vaginalis}

The pooled prevalence of $T$ vaginalis infection was $29.1 \%$ (95\% CI, 20.9\%$37.2 \%$ ) among women in East and Southern Africa, compared with $17.8 \%$ (95\% CI, 12.4\%-23.1\%) in West and Central Africa. The highest point estimate in East and Southern Africa was $51.7 \%$ (95\% CI, 41.9\%-61.5\%), reported in a refugee camp of Rwandans in Tanzania, ${ }^{17}$ as diagnosed by wetmount microscopy. The highest prevalence estimate in West and Central Africa, $52.0 \%$ (95\% CI, 47.6\%-56.4\%), was in Jos, Nigeria, where T vaginalis was identified by the same method. ${ }^{18}$

Figure 2. Curable STI/RTI and Malaria Infection Among Pregnant Women Attending Antenatal Facilities in Africa by Subregion

East and Southern Africa

$\begin{array}{lcr}\text { Infection } & \text { Positive } & \\ \text { Syphilis } & \text { Diagnosis } & \text { Tested } \\ \text { Neisseria gonorrhoeae } & 8346 & 136686 \\ \text { Chlamydia trachomatis } & 626 & 17220 \\ \text { Trichomonas vaginalis }_{\text {Bacterial vaginosis }} & 550 & 5159 \\ \text { Peripheral malaria } & 4280 & 28189 \\ \text { Placental malaria }^{\text {a }} & 11688 & 14112 \\ & 1388 & 6649 \\ & & \end{array}$

$\begin{array}{cc}\begin{array}{c}\text { Pooled Prevalence } \\ \text { Estimates, \% (95\% Cl) }\end{array} & \begin{array}{c}\text { Lowest to Highest Point } \\ \text { Estimates, Range, \% }\end{array} \\ 4.50(3.90-5.10) & 0.10-13.70 \\ 3.70(2.80-4.60) & 1.40-23.30 \\ 6.90(5.10-8.60) & 2.00-23.20 \\ 29.10(21.00-37.20) & 3.90-51.70 \\ 50.80(43.30-58.40) & 23.50-85.50 \\ 32.00(25.90-38.00) & 2.10-87.90 \\ 25.80(19.70-31.90) & 8.50-74.70\end{array}$

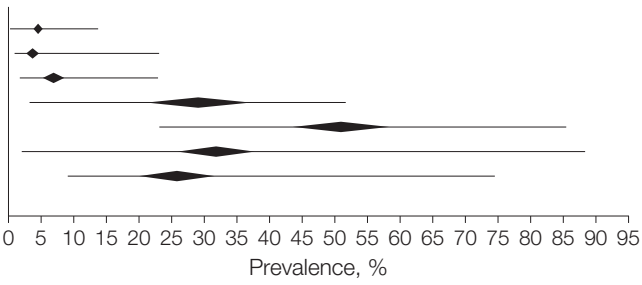

West and Central Africa

\begin{tabular}{lcr} 
Infection & $\begin{array}{c}\text { Positive } \\
\text { Diagnosis }\end{array}$ & \multicolumn{1}{c}{ Tested } \\
Syphilis & 851 & 10797 \\
Neisseria gonorrhoeae & 73 & 2737 \\
Chlamydia trachomatis & 357 & 5414 \\
Trichomonas vaginalis & 822 & 9806 \\
Bacterial vaginosis & 1208 & 7435 \\
Peripheral malaria & 12242 & 43312 \\
Placental malaria $^{a}$ & 4658 & 27535
\end{tabular}

$\begin{array}{cc}\begin{array}{c}\text { Pooled Prevalence } \\ \text { Estimates, \% (95\% Cl) }\end{array} & \begin{array}{c}\text { Lowest to Highest Point } \\ \text { Estimates, Range, \% }\end{array} \\ 3.50(1.80-5.20) & 0.10-16.30 \\ 2.70(1.70-3.70) & 1.60-4.60 \\ 6.10(4.00-8.30) & 1.40-16.40 \\ 17.80(12.40-23.10) & 1.60-52.00 \\ 37.60(18.00-57.20) & 18.00-74.50 \\ 38.20(37.30-44.10) & 0.90-94.50 \\ 39.90(34.20-45.70) & 9.00-91.60\end{array}$

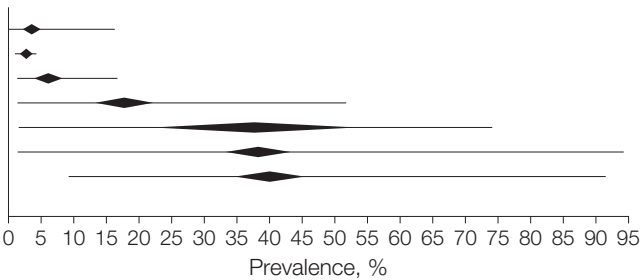

Diamonds indicate pooled mean prevalence estimates; the extremes of the diamonds indicate $95 \%$ Cls. Horizontal bars indicate lowest to highest point prevalence estimates. STI/RTI indicates sexually transmitted infection/reproductive tract infection.

a Placental malaria is measured at delivery. 


\section{Bacterial Vaginosis}

The burden of bacterial vaginosis was higher than any other STI/RTI in both subregions. In East and Southern Africa, the pooled prevalence estimate was $50.8 \%$ (95\% CI, 43.4\%-58.4\%). The highest point estimate was $85.5 \%(95 \%$ CI, $82.8 \%-88.1 \%$ ) in Blantyre, Malawi, where Amsel criteria were used for diagnosis. ${ }^{17}$ In West and Central Africa, the pooled prevalence estimate was $37.6 \%$ (95\% CI, 18.0\%-57.2\%), with the highest point estimate at $74.5 \%(95 \%$ CI, 70.0\%-79.1\%) in Praia, Cape Verde, based on clue cell count. ${ }^{19}$

\section{Malaria}

Peripheral Malaria. The pooled prevalence of peripheral malaria in East and Southern Africa was 32.0\% (95\% CI, $25.9 \%-38.0 \%)$. The highest subregional prevalence, $87.9 \%(95 \% \mathrm{CI}$, $85.7 \%-90.1 \%$ ), was reported from Hoima, Uganda, where diagnosis was made by microscopy. ${ }^{20}$ In West and Central Africa, the pooled prevalence of peripheral malaria parasitemia was $38.2 \%$ (95\% CI, 32.3\%-44.1\%). The highest point estimate was $94.9 \%$ (95\% CI, 88.0\%-102.0\%) in Ngali II, Cameroon, as identified by polymerase chain reaction (PCR) diagnosis. ${ }^{21}$

Placental Malaria. For placental malaria, measurable only after delivery, the pooled prevalence in East and Southern Africa was $25.8 \%$ (95\% CI, 19.7\%$31.9 \%$ ); the highest point estimate, $74.7 \%$ (95\% CI, 65.5\%-84.0\%), was based on histological diagnosis in Kisumu, Kenya. ${ }^{22}$ In West and Central Africa, the pooled prevalence was $39.9 \%$ (95\% CI, $34.2 \%-45.7 \%$ ), and the highest point prevalence was $91.6 \%$ (95\% CI, 84.8\%$94.4 \%$ ) as diagnosed by placental histology, impression, and smears with microscopy in Ebolowa, Cameroon. ${ }^{23}$

\section{Dual Prevalence of STIs/RTIs and Malaria}

Only 5 publications reported the prevalence of syphilis and malaria, ${ }^{24-28}$ and no single article reported coinfection of malaria and STIs/RTIs. Subanalysis in a prospective cohort study of pregnant women in Tanzania provided some of the only published data on coinfection: $48.3 \%$ of RPR-positive women also had placental parasitemia and $35.0 \%$ of RPR-negative women had malariainfected placentas $(P<.001){ }^{29}$

\section{COMMENT}

This systematic review of STIs/RTIs and malaria prevalence estimates over a 20year period suggests that a considerable burden of malaria and STIs/RTIs exists at the population level among pregnant women attending antenatal facilities in sub-Saharan Africa. However, the absence of reports on coinfection makes it impossible to describe the prevalence of malaria only, curable STIs/RTIs only, or coinfection in pregnancy.

The GRADE approach to data quality assessment ${ }^{30}$ was considered inappropriate for this particular metaanalysis. It is a useful and transparent tool for the analysis of treatment outcomes following contrasting interventions produced by different study designs. However, because we included studies that had open enrollment in the antenatal care setting and we were not investigating the effect of medical intervention, we did not expect the population prevalence of STIs/RTIs and malaria in pregnancy to vary across study designs. In addition, the GRADE system requires ranking of evidence by outcomes of interest, scored as high, intermediate, low, or very low. In this review, we could have assigned quality scores to point prevalence estimates, but that would have introduced a limited but unavoidable level of subjectivity. Thus, we chose instead to improve the precision of each point estimate with a standard $\operatorname{method}^{9}$ for correcting errors of known magnitude before incorporating data into the random-effects models. This same approach has been used with prevalence data from Tanzania to compare STI/RTI estimates derived by disparate diagnostic tests. ${ }^{31} \mathrm{We}$ present corrected and uncorrected point prevalence estimates by study in eTable 1 through eTable 7.

Diagnostic methods and tools have changed for many pathogens during the period covered in this review. The advent of molecular tests such as PCR and ligase chain reaction has allowed researchers in recent years to detect infection where older diagnostic methods may have failed to do so. Although our statistical correction for diagnostic errors can make data more comparable, the pooled mean prevalence of STIs/RTIs and malaria is still probably an underestimate of the true burden of disease. Among 59 studies providing estimates for syphilis prevalence, 45 used the nontreponemal RPR or venereal disease research laboratory tests confirmed by a Treponema-specific test, reflecting wide acceptance of the diagnostic gold standard. Because biological false-positive nontreponemal test results can be produced by malaria and other infections, the burden of syphilis in studies that did not use treponemal confirmatory testing may be overstated.

A variety of diagnostic methods were used for identifying $N$ gonorrhoeae and C trachomatis infections, whereas wetmount microscopy was used in all but 2 studies reporting trichomoniasis prevalence, a method notoriously lacking sensitivity compared with culture or molecular tests. ${ }^{32,33}$ Bacterial vaginosis was diagnosed using 4 methods: Nugent score, Spiegel criteria, Amsel criteria, and clue cell prevalence estimates. The $\mathrm{Nu}$ gent score ${ }^{34}$ is the preferred objective method and was used in studies reporting the 7 highest rates of infection from East and Southern Africa. Thus, the pooled mean prevalence would likely have been higher had the Nugent score been used in all studies.

Peripheral parasitemia may be underrepresented for 2 reasons. Infection tends to be highest between gestational weeks 9 through 16, declining until term..$^{35,36}$ No studies appeared to have measured peripheral parasitemia during this peak period. Another important source of underestimated disease burden is that most malaria diagnoses were based on microscopy without molecular test correction. A study in Blantyre, Malawi, illustrates the extent to which underdiagnosis may occur with conventional microscopy; the

JAMA, May 16, 2012-Vol 307, No. $192 \mathbf{2 0 8 3}$ 
prevalence of peripheral parasitemia of $51.9 \%$ (95\% CI, 43.4\%-60.3\%) was found by PCR, while microscopy detected infection only in $14.9 \%$ (95\% CI, $11.8 \%-18.0 \%)$ of pregnant women. ${ }^{37}$

The dual prevalence of STIs/RTIs and malaria varied in the subregions we analyzed. Overall, East and Southern Africa has a greater burden of STIs/RTIs compared with West and Central Africa. Several factors that are linked to exposure may contribute to this difference, including higher prevalence of STIs/RTIs circulating at the community level, patterns of male circumcision as well as sexual behavior related to age of sexual debut, age at first marriage, premarital sex, and number of total partners and concurrent sex partners. The prevalence of HIV, for example, remains substantially higher in East and Southern Africa compared with the West and Central subregion. According to the Joint United Nations Programme on HIV/AIDS, 34\% of the world's HIV-positive population was living in 10 countries of Southern Africa in 2010. ${ }^{38}$ The epidemic in East Africa has declined over the past decade, but HIV prevalence remains higher than in West and Central Africa.

Peripheral and placental malaria is slightly higher in West and Central Africa compared with the East and Southern subregion. This may be due to greater seasonal variation in transmission within West and Central Africa. Recent declines in malaria transmission within selected locales of Africa will likely translate into fewer pregnant women acquiring immunity from one pregnancy to the next. Thus, all women in their reproductive years (rather than just those in their first or second pregnancies) may remain vulnerable to malaria in the years ahead until the absolute risk of exposure is negligible.

Human immunodeficiency virus and malaria interact to increase parasitic infection of the placenta and incidence of low birth weight. ${ }^{39}$ Plasmodium falciparum infection also increases viral load among HIV-positive pregnancy women. ${ }^{40}$ New evidence suggests that malaria parasites are more likely to develop wildtype mutations following exposure to

2084 JAMA, May 16, 2012-Vol 307, No. 19 sulfadoxine-pyrimethamine as intermittent preventive treatment during pregnancy (IPTp) when administered to HIVpositive women. ${ }^{41}$ The interaction between STIs/RTIs and HIV has been well established, although providing presumptive treatment for STIs/RTIs to pregnant women in Rakai, Uganda, has not shown protective effect against maternal to child transmission of HIV. ${ }^{42}$ However, malaria chemoprophylaxis was not provided in this study; therefore, the potential modulating effect of malaria on maternal to child transmission in the presence of STIs/RTIs remains unknown.

Our study has several limitations. An unavoidable but important limitation is the inherent delay between gathering evidence at the clinic level and public dissemination. This is important in our study because HIV prevention campaigns, including STI/RTI screening and treatment programs, have made inroads in reducing transmission in many settings. To capture these reductions with greater precision, more recent data are needed. Another limitation is that even after stratifying by geography and age of study, heterogeneity among studies persisted. The random-effects models, in turn, produced wide $95 \%$ confidence intervals in some instances. In addition, because we relied on evidence from English-language sources and abstracts that had been translated into English, we may have identified fewer studies from researchers who publish in other languages.

There is a major risk of adverse birth outcomes associated with malaria and STIs/RTIs in pregnancy. More than 30 million pregnant women are at risk of infection each year in sub-Saharan Africa. ${ }^{43} \mathrm{Ma}$ laria is associated with intrauterine growth retardation, preterm delivery, low birth weight, ${ }^{44,45}$ stillbirth, ${ }^{44}$ early neonatal death ${ }^{44}$ and maternal anemia. ${ }^{45}$ In Tanzania, T pallidum is associated with $51 \%$ of stillbirths and $24 \%$ of preterm live births. ${ }^{46}$ Neisseria gonorrhoeae is associated with a 2-fold increase in the risk of preterm delivery, ${ }^{47}$ whereas the risk of early preterm delivery in the presence of C trachomatis infection is 4 times higher. ${ }^{48}$
Untreated $C$ trachomatis infects the eyes of $50 \%$ of newborns at delivery, and pneumonia will develop in $10 \%$ to $20 \%$ of these infants. ${ }^{49,50}$ Neisseria gonorrhoeae and $C$ trachomatis are common causes of ophthalmia neonatorum and may lead to corneal scarring and blindness if untreated. Trichomonas vaginalis infection is associated with a 2-fold increase in preterm delivery, ${ }^{51}$ as is bacterial vaginosis, the odds of which are 7 times higher when the condition manifests prior to 16 weeks' gestation. ${ }^{52}$ Bacterial vaginosis is also significantly associated with the risk of spontaneous abortion..$^{52}$ Within this context, progress toward the maternal and child health targets of Millennium Development Goals may be possible by improving malaria andSTI/RTI control measures within the antenatal care package.

Several current infection control strategies are included in the antenatal care package. In areas of stable malaria transmission, WHO recommends that pregnant women sleep under insecticidetreated mosquito bed nets and receive 2 to 3 treatment courses of SP-IPTp during antenatal consultations. Drug resistance to SP has compromised the protective effect of SP-IPTp in recent years, prompting a need to identify efficacious drugs and new strategies to prevent malaria in pregnancy. ${ }^{53}$

WHO recommends syphilis screening and treatment for pregnant women at their first antenatal visit. For other curable STIs/RTIs, WHO suggests using syndrome-based algorithms to guide diagnosis and treatment. However, the vast majority of gonococcal (80\%) and chlamydial (70\%-75\%) infections in women are asymptomatic ${ }^{54}$ and therefore never diagnosed. Consequently, the algorithm based on vaginal discharge syndrome has a low sensitivity (30\%-80\%) and specificity (40\%-80\%) for $\mathrm{N}$ gonorrhoeae and $C$ trachomatis among pregnant women. ${ }^{55-57}$ Syndromic management has slightly higher sensitivity for T vaginalis (54\%-83\%) and bacterial vaginosis (51\%-69\%), with moderate specificity (40\%-54\% for T vaginalis and 40\%$58 \%$ for bacterial vaginosis). ${ }^{58}$

In addition, potential new directions for the antenatal care package have been 
suggested, including use of novel drugs and rapid diagnostic tests. Several trials of azithromycin-based combination therapies are under investigation for use in IPTp. Azithromycin has modest antimalarial properties but needs a partner antimalarial drug against $P$ falciparum $.^{59} \mathrm{De}-$ spite concerns about drug resistance, ${ }^{60} \mathrm{a}$ 2 -g dose of azithromycin has resulted in cure rates of $97.7 \%$ (95\% CI, 94.0\%99.4\%) of syphilis cases in a study in Tanzania. ${ }^{61}$ A single 2-g dose of azithromycin was $98.9 \%$ (95\% CI, $97.9 \%-100 \%$ ) efficacious against $N$ gonorrhoeae in the United States, ${ }^{62}$ while meta-analysis showed that $1 \mathrm{~g}$ cures $96.5 \%$ (95\% CI, 95.3\%-97.7\%) of C trachomatis infections. ${ }^{63}$ A trial in Malawi using $1 \mathrm{~g}$ of azithromycin administered twice with SPIPTp reduced the risk of $T$ vaginalis $35 \%$ ( $P=.02) .{ }^{64}$ Azithromycin-based combinations could protect against bacterial vaginosis if administered early in pregnancy; a meta-analysis of antibiotic therapy for the treatment of bacterial vaginosis in pregnancy prior to gestational week 20 is associated with a significant reduction in the risk of preterm birth. ${ }^{65}$

Novel use of rapid diagnostic tests may replace IPTp with sulfadoxinepyrimethamine altogether if used for intermittent screening and treatment for malaria during antenatal visits. Intermittent screening and treatment with artesunateamodiaquine was noninferior to IPTp with sulfadoxine-pyrimethamine in Ghana in an area wheresulfadoxine-pyrimethamine resistance was low; the incidence of low birth weight was similar between the IPTp with sulfadoxine-pyrimethamine and intermittent screening and treatment groups among multigravid mothers ( $11.3 \%$ vs $11.3 \%$ ) and among primigravid mothers (16.1\% vs $17.2 \%) .{ }^{66}$ Rapid point-of-care tests for HIV have revolutionized the uptake and performance of voluntary counseling and testing ${ }^{67}$ and are used in some antenatal settings in Africa. Point-of-care tests for syphilis are increasingly available, making possible same-day results and prompt treatment. ${ }^{68,69}$

Mitigating the dual prevalence of malaria and STIs/RTIs will require improvements in the Safe Motherhood package. ${ }^{70}$ Bacterial vaginosis requires particular at- tention given its high prevalence. Clinical trials are needed to investigate the protective effect of presumptive treatment of bacterial vaginosis with metronidazole at time points that are biologically optimal and operationally feasible. It is less clear whether pregnancy outcomes would be improved more with point-of-care tests and treatment for HIV, syphilis, and malaria, while syndromic management is provided for the remaining curable STIs/ RTIs—or if maternal, fetal, and newborn health will be better if women are given point-of-care tests for HIV and syphilis along with azithromycin-based combination therapy in IPTp. Rigorously conducted clinical trials are urgently needed.

\section{CONCLUSION}

The dual prevalence of malaria and STIs/RTIs is evident among pregnant women who attend antenatal facilities in sub-Saharan Africa. As malaria control and elimination efforts are brought to scale, the relative contribution of STIs/RTIs to adverse birth outcomes most likely will increase proportionately. Coinfection prevalence estimates for malaria and STIs/RTIs need to be established and routinely reported. Rigorous studies using molecular diagnostic methods are needed to characterize more accurately the prevalence of these infections and their clinical consequences. Clinical trials are needed to compare birth outcomes, operational feasibility/acceptability, and cost-effectiveness of IPTp with azithromycin-based combination therapy against an approach of integrated screening and treatment for malaria and STIs/RTIs.

Author Contributions: Mr Chico and Dr Chandramohan had full access to all of the data in the study and take responsibility for the integrity of the data and the accuracy of the data analysis.

Study concept and design: Chandramohan.

Acquisition of data: Chico.

Analysis and interpretation of data: Chico, Mayaud, Mabey, Ariti, Ronsmans, Chandramohan.

Drafting of the manuscript: Chico.

Critical revision of the manuscript for important intellectual content: Chico, Mayaud, Mabey, Ariti, Ronsmans, Chandramohan.

Statistical analysis: Chico, Ariti.

Administrative, technical, or material support: Chico, Mayaud, Mabey, Ariti, Ronsmans, Chandramohan. Study supervision: Chandramohan.

Conflict of Interest Disclosures: All authors have completed and submitted the ICMJE Form for Disclosure of Potential Conflicts of Interest. Mr Chico reports having previously received funding as part of 2 studies co-financed by Pfizer and the Medicines for Malaria Venture that are investigating the use of azithromycin plus chloroquine in IPTp. No other disclosures were reported.

Online-Only Material: eAppendixes 1 through 3, eTables 1 through 7 , and eFigures 1 through 7 are available at http://www.jama.com.

Additional Contributions: We are grateful to Rosanna Peeling, PhD, London School of Hygiene and Tropical Medicine, for reviewing the data and assisting in the classification of methods by quality, and Mythili Ramakrishna, BDS, MSc, London School of Hygiene and Tropical Medicine, for screening studies against inclusion/exclusion criteria separately from $\mathrm{Mr}$ Chico. Dr Ramakrishna was compensated for her contribution. No other compensation was received.

\section{REFERENCES}

1. Stanton C, Lawn JE, Rahman H, Wilczynska-Ketende K, Hill K. Stillbirth rates: delivering estimates in 190 countries. Lancet. 2006;367(9521):1487-1494.

2. Black RE, Cousens S, Johnson HL, et al; Child Health Epidemiology Reference Group of WHO and UNICEF. Global, regional, and national causes of child mortality in 2008: a systematic analysis. Lancet. 2010; 375(9730):1969-1987.

3. McCormick MC. The contribution of low birth weight to infant mortality and childhood morbidity. N Engl J Med. 1985;312(2):82-90.

4. Goldenberg RL, Thompson C. The infectious origins of stillbirth. Am J Obstet Gynecol. 2003;189 (3):861-873.

5. Zhou X, Brotman RM, Gajer $P$, et al. Recent advances in understanding the microbiology of the female reproductive tract and the causes of premature birth. Infect Dis Obstet Gynecol. 2010;2010:737425. 6. Mullick S, Watson-Jones D, Beksinska M, Mabey D. Sexually transmitted infections in pregnancy: prevalence, impact on pregnancy outcomes, and approach to treatment in developing countries. Sex Transm Infect. 2005;81(4):294-302.

7. Desai M, ter Kuile FO, Nosten F, et al. Epidemiology and burden of malaria in pregnancy. Lancet Infect Dis. 2007;7(2):93-104.

8. Sterne JAC, Egger M, Davey Smith G. Investigating and dealing with publication and other bias. In: Egger M, Smith GD, Altman DG, eds. Systematic Reviews in Health Care: Meta-Analysis in Context. 2nd ed. London, England: BMJ Books; 2001:189-208. 9. Kelsey JL, Whittemore AS, Evans AS, Thompson WD. Methods in Observational Epidemiology. 2nd ed. New York, NY: Oxford University Press; 1996. 10. DerSimonian R, Laird N. Meta-analysis in clinical trials. Control Clin Trials. 1986;7(3):177-188.

11. Sterne J. Meta-analysis in Stata: An Updated Collection From the Stata Journal. College Station, TX: Stata Press; 2009.

12. Vuylsteke B, Bastos R, Barreto J, et al. High prevalence of sexually transmitted diseases in a rural area in Mozambique. Genitourin Med. 1993;69(6): 427-430.

13. Mbopi Kéou FX, Mbu R, Mauclère $P$, et al. Antenatal HIV prevalence in Yaounde, Cameroon. Int J STD AIDS. 1998;9(7):400-402.

14. Diallo $M O$, Ettiègne-Traoré $V$, Maran $M$, et al. Sexually transmitted diseases and human immunodeficiency virus infections in women attending an antenatal clinic in Abidjan, Côte d'Ivoire. Int J STD AIDS 1997;8(10):636-638.

15. Ortashi OM, El Khidir I, Herieka E. Prevalence of HIV, syphilis, Chlamydia trachomatis, Neisseria gonorrhoeae, Trichomonas vaginalis and candidiasis among pregnant women attending an antenatal clinic in Khartoum, Sudan. J Obstet Gynaecol. 2004; 24(5):513-515.

16. Van Dyck E, Samb N, Sarr AD, et al. Accuracy of 
2 enzyme immunoassays and cell culture in the detection of Chlamydia trachomatis in low and high risk populations in Senegal. Eur J Clin Microbiol Infect Dis. 1992;11(6):527-534

17. Mayaud P, Msuya W, Todd J, et al. STD rapid assessment in Rwandan refugee camps in Tanzania. Genitourin Med. 1997;73(1):33-38

18. Ogbonna $\mathrm{Cl}$, Ogbonna IB, Ogbonna AA, Anosike JC. Studies on the incidence of Trichomonas vaginalis amongst pregnant women in Jos area of Plateau State, Nigeria. Angew Parasitol. 1991;32(4):198204

19. Wessel HF, Herrmann B, Dupret A, Moniz F, Brito $C$, Bergström S. Genital infections among antenatal care attendees in Cape Verde. Afr J Reprod Health. 1998;2(1):32-40.

20. Ndyomugyenyi R, Magnussen P. Anaemia in pregnancy: Plasmodium falciparum infection is an important cause in primigravidae in Hoima district, western Uganda. Ann Trop Med Parasitol. 1999;93(5): 457-465.

21. Leke RF, Bioga JD, Zhou J, et al. Longitudinal studies of Plasmodium falciparum malaria in pregnant women living in a rural Cameroonian village with high perennial transmission. Am J Trop Med Hyg. 2010; 83(5):996-1004.

22. Kassam SN, Nesbitt S, Hunt LP, Oster N, Soothill $P$, Sergi C. Pregnancy outcomes in women with or without placental malaria infection. Int J Gynaecol Obstet. 2006:93(3):225-232

23. Cot $M$, Le Hesran JY, Miailhes $P$, Esveld M, Etya'ale $D$, Breart G. Increase of birth weight following chloroquine chemoprophylaxis during the first pregnancy: results of a randomized trial in Cameroon. Am J Trop Med Hyg. 1995;53(6):581-585.

24. Ayisi JG, van Eijk AM, ter Kuile FO, et al. Risk factors for HIV infection among asymptomatic pregnant women attending an antenatal clinic in western Kenya. Int J STD AIDS. 2000;11(6):393-401. 25. Luján J, de Oñate WA, Delva W, et al. Prevalence of sexually transmitted infections in women attending antenatal care in Tete province, Mozambique. S Afr Med J. 2008;98(1):49-51

26. Menéndez $C$, Castellsagué $X$, Renom $M$, et al. Prevalence and risk factors of sexually transmitted infections and cervical neoplasia in women from a rural area of southern Mozambique. Infect Dis Obstet Gynecol. 2010;2010:609315. doi:10.1155/2010 1609315

27. Montoya PJ, Lukehart SA, Brentlinger PE, et al. Comparison of the diagnostic accuracy of a rapid immunochromatographic test and the rapid plasma reagin test for antenatal syphilis screening in Mozambique. Bull World Health Organ. 2006; 84(2):97-104.

28. van den Broek NR, White SA, Goodall $M$, et al. The APPLE study: a randomized, community-based, placebo-controlled trial of azithromycin for the prevention of preterm birth, with meta-analysis. PLoS Med. 2009;6(12):e1000191.

29. Watson-Jones D, Weiss HA, Changalucha JM, et al Adverse birth outcomes in United Republic of Tanzania-impact and prevention of maternal risk factors. Bull World Health Organ. 2007;85(1): 9-18.

30. Guyatt $G H$, Oxman AD, Vist GE, et al: GRADE Working Group. GRADE: an emerging consensus on rating quality of evidence and strength of recommendations. BMJ. 2008;336(7650):924926.

31. Orroth KK, Korenromp EL, White RG, et al. Comparison of STD prevalences in the Mwanza, Rakai, and Masaka trial populations: the role of selection bias and diagnostic errors. Sex Transm Infect. 2003;79(2): 98-105.

32. Fouts AC, Kraus SJ. Trichomonas vaginalis: reevaluation of its clinical presentation and laboratory diagnosis. J Infect Dis. 1980;141(2):137-143.
33. van Der Schee C, van Belkum A, Zwijgers L, et al. Improved diagnosis of Trichomonas vaginalis infection by PCR using vaginal swabs and urine specimens compared to diagnosis by wet mount microscopy, culture, and fluorescent staining. J Clin Microbiol. 1999:37(12):4127-4130.

34. Nugent RP, Krohn MA, Hillier SL. Reliability of diagnosing bacterial vaginosis is improved by a standardized method of Gram stain interpretation. J Clin Microbiol. 1991;29(2):297-301.

35. Brabin BJ. An analysis of malaria in pregnancy in Africa. Bull World Health Organ. 1983;61(6):10051016

36. Brabin B. The Risks and Severity of Malaria in Pregnant Women: Applied Field Research in Malaria Reports. Geneva, Switzerland: Special Programme for Research and Training in Tropical Diseases, World Health Organization; 1991.

37. Mankhambo L, Kanjala M, Rudman S, Lema VM, Rogerson SJ. Evaluation of the OptiMAL rapid antigen test and species-specific PCR to detect placental Plasmodium falciparum infection at delivery. J Clin Microbiol. 2002;40(1):155-158.

38. Joint United Nations Programme on HIV/AIDS. Report on the Global AIDS Epidemic 2010. Geneva, Switzerland: Joint United Nations Programme on HIV/AIDS; 2010.

39. Ayisi JG, van Eijk AM, ter Kuile FO, et al. The effect of dual infection with HIV and malaria on pregnancy outcome in western Kenya. AIDS. 2003; 17(4):585-594.

40. Ayisi JG, van Eijk AM, Newman RD, et al. Maternal malaria and perinatal HIV transmission, western Kenya. Emerg Infect Dis. 2004;10(4):643-652. 41. Menéndez C, Serra-Casas E, Scahill MD, et al. HIV and placental infection modulate the appearance of drug-resistant Plasmodium falciparum in pregnant women who receive intermittent preventive treatment. Clin Infect Dis. 2011;52(1):41-48.

42. Gray RH, Wabwire-Mangen F, Kigozi G, et al. Randomized trial of presumptive sexually transmitted disease therapy during pregnancy in Rakai, Uganda. Am J Obstet Gynecol. 2001;185(5):1209-1217.

43. Dellicour S, Tatem AJ, Guerra CA, Snow RW, ter Kuile FO. Quantifying the number of pregnancies at risk of malaria in 2007: a demographic study. PLoS Med. 2010;7(1):e1000221.

44. van Geertruyden JP, Thomas F, Erhart A $D^{\prime}$ Alessandro $U$. The contribution of malaria in pregnancy to perinatal mortality. Am J Trop Med Hyg. 2004; 71(2)(suppl):35-40

45. Kalilani L, Mofolo I, Chaponda M, Rogerson S, Meshnick S. The effect of timing and frequency of malaria infection during pregnancy on low birth weight and maternal anemia. Am J Trop Med Hyg. 2006; 75(5):414.

46. Watson-Jones D, Changalucha J, Gumodoka B, et al. Syphilis in pregnancy in Tanzania, I: impact of maternal syphilis on outcome of pregnancy. J Infect Dis. 2002;186(7):940-947.

47. Goldenberg RL, Culhane JF, lams JD, Romero R. Epidemiology and causes of preterm birth. Lancet. 2008:371(9606):75-84

48. Rours GI, Duijts L, Moll HA, et al. Chlamydia trachomatis infection during pregnancy associated with preterm delivery: a population-based prospective cohort study. Eur J Epidemiol. 2011;26(6):493-502. 49. Schachter J, Grossman M, Sweet RL, Holt J, Jordan C, Bishop E. Prospective study of perinatal transmission of Chlamydia trachomatis. JAMA. 1986;255 (24):3374-3377.

50. Hammerschlag MR. Chlamydial and gonococcal infections in infants and children. Clin Infect Dis. 2011; 53(suppl 3):S99-S102

51. French JI, McGregor JA, Parker R. Readily treatable reproductive tract infections and preterm birth among black women. Am J Obstet Gynecol. 2006; 194(6):1717-1726
52. Leitich $H$, Bodner-Adler $B$, Brunbauer $M$, Kaider A, Egarter $C$, Husslein $P$. Bacterial vaginosis as a risk factor for preterm delivery: a meta-analysis. Am J Obstet Gynecol. 2003;189(1):139-147.

53. Chico RM, Chandramohan D. Intermittent preventive treatment of malaria in pregnancy: at the crossroads of public health policy. Trop Med Int Health 2011;16(7):774-785.

54. World Health Organization. Global Prevalence and Incidence of Selected Curable Sexually Transmitted Infections: Overview and Estimates. Geneva, Switzerland: World Health Organization; 2001.

55. Mayaud P, ka-Gina G, Cornelissen J, et al. Validation of a WHO algorithm with risk assessment for the clinical management of vaginal discharge in Mwanza, Tanzania. Sex Transm Infect. 1998;74 (suppl 1):S77-S84

56. Vuylsteke B, Laga $M$, Alary $M$, et al. Clinical algorithms for the screening of women for gonococcal and chlamydial infection: evaluation of pregnant women and prostitutes in Zaire. Clin Infect Dis. 1993 17(1):82-88.

57. Costello Daly C, Wangel AM, Hoffman IF, et al. Validation of the WHO diagnostic algorithm and develop ment of an alternative scoring system for the management of women presenting with vaginal discharge in Malawi. Sex Transm Infect. 1998;74(suppl 1):S50 S58.

58. Tann CJ, Mpairwe H, Morison L, et al. Lack of effectiveness of syndromic management in targeting vaginal infections in pregnancy in Entebbe, Uganda. Sex Transm Infect. 2006;82(4):285-289.

59. Chico RM, Pittrof R, Greenwood B, Chandramohan D. Azithromycin-chloroquine and the intermittent preventive treatment of malaria in pregnancy. Malar J. 2008 7(1):255.

60. Mabey D. Azithromycin resistance in Treponema pallidum. Sex Transm Dis. 2009:36(12):777-778.

61. Riedner G, Rusizoka M, Todd J, et al. Single-dose azithromycin vs penicillin $G$ benzathine for the treatment of early syphilis. N Engl J Med. 2005;353(12) 1236-1244.

62. Handsfield HH, Dalu ZA, Martin DH, Douglas JM Jr, McCarty JM, Schlossberg D; Azithromycin Gonorrhea Study Group. Multicenter trial of single-dose azithromycin vs ceftriaxone in the treatment of uncomplicated gonorrhea. Sex Transm Dis. 1994;21(2):107111.

63. Lau CY, Qureshi AK. Azithromycin vs doxycycline for genital chlamydial infections: a meta-analysis of randomized clinical trials. Sex Transm Dis. 2002;29(9): 497-502.

64. Luntamo $M$, Kulmala $T$, Mbewe $B$, Cheung YB, Maleta K, Ashorn P. Effect of repeated treatment of preg nant women with sulfadoxine-pyrimethamine and azithromycin on preterm delivery in Malawi: a random ized controlled trial. Am J Trop Med Hyg. 2010; 83(6):1212-1220.

65. McDonald HM, Brocklehurst P, Gordon A. Antibiotics for treating bacterial vaginosis in pregnancy. Cochrane Database Syst Rev. 2007;(1):CD000262.

66. Tagbor $\mathrm{H}$, Bruce J, Agbo M, Greenwood B Chandramohan D. Intermittent screening and treatment vs intermittent preventive treatment of malaria in pregnancy: a randomised controlled non-inferiority trial. PLoS One. 2010;5(12):e14425.

67. Dewsnap $\mathrm{CH}, \mathrm{Mcowan} \mathrm{A}$. A review of HIV pointof-care tests. Int J STD AIDS. 2006;17(6):357-359.

68. Peeling R. The Sexually Transmitted Diseases Diagnostics Initiative: Laboratory Based Evaluation of Rapid Syphilis Diagnostics. Geneva, Switzerland: World Health Organization; 2003.

69. Peeling RW, Ye H. Diagnostic tools for preventing and managing maternal and congenital syphilis: an overview. Bull World Health Organ. 2004;82(6): 439-446.

70. Mahler H. The Safe Motherhood initiative: a call to action. Lancet. 1987;1(8534):668-670. 